\title{
SUSTENTABILIDADE AMBIENTAL NO CONTEXTO HOSPITALAR: ESTUDO EM UM HOSPITAL DO RIO GRANDE DO SUL ${ }^{1}$
}

\section{ENVIRONMENTAL SUSTAINABILITY IN THE HOSPITAL CONTEXT: STUDY IN A HOSPITAL OF RIO GRANDE DO SUL}

\section{SOSTENIBILIDAD AMBIENTAL EN EL CONTEXTO DE HOSPITALES: UN ESTUDIO EN HOSPITAL DE RIO GRANDE DO SUL}

Carlos Eduardo Alarcon Pizzorno

Universidade Federal de Santa Catarina - UFSC

carlospizzorno14@yahoo.com.br

Elisete Dahmer Pfitscher

Universidade Federal de Santa Catarina - UFSC

elisete@cse.ufsc.br

\author{
Vivian Osmari Uhlmann \\ Universidade Federal de Santa Catarina - UFSC \\ vouhlmann@gmail.com
}

\begin{abstract}
Resumo
O objetivo geral do estudo consiste em verificar a sustentabilidade ambiental de um hospital do Estado do Rio Grande do Sul, por meio da aplicação parcial do Sistema Contábil Gerencial Ambiental-SICOGEA-Geração 3. O processo de coleta de dados ocorreu com a aplicação de uma lista de verificação, com 134 questões divididas por grupos-chave e subgrupos. Com base nos resultados alcançados, foi verificado um índice de sustentabilidade geral de $30,60 \%$, que é considerado fraco. Isto indica que o processo de prestação dos serviços hospitalares pode estar causando impactos ambientais negativos. Cabe ressaltar que o grupo-chave que mais contribuiu para o índice geral foi o de "Prestação de Serviço", com 35,61\%. Por outro lado, o grupo-chave que apresentou o pior resultado foi "Finanças e Contabilidade", com 12,78\%, isto se deve ao fato do hospital não possuir um Sistema de Gestão Ambiental, tampouco existir um plano de qualidade ambiental. Após identificar os pontos críticos quanto à sustentabilidade, estruturou-se um Plano Resumido de Gestão Ambiental, que contemplou ações para melhorar o desempenho ambiental, como a de elaborar e implantar um manual com metas e indicadores de eficiência.
\end{abstract}

Palavras-chave: Sustentabilidade Ambiental. Hospital. Contabilidade Ambiental.

\begin{abstract}
The aim of this study is to verify the environmental sustainability of a hospital in the state of Rio Grande do Sul, through the partial implementation of Environmental Management Accounting System - SICOGEA - Generation 3. The process of data collection occurred with the application of a checklist, with 134 questions divided by key groups and subgroups. Based on the results achieved, there was an overall sustainability index of 30.60\%, which is considered weak. This indicates that the process of provision of hospital services may be causing negative environmental impacts. It should be noted that the key group that contributed most to the overall index was the "Service Delivery", with 35.61\%. On the other hand, the key group that presented the worst result was "Finance and Accounting," with 12.78\%, this is because the hospital does not have an Environmental Management System, either there is a plan of environmental quality. After identifying the critical points with respect to sustainability is a structured Environmental Management Plan Summary, which included actions to improve environmental performance, such as design and implement a manual with clear targets and indicators.
\end{abstract}

Keywords: Environmental Sustainability. Hospital. Environmental Accounting.

\footnotetext{
${ }^{1}$ Submetido em 29 de julho de 2012. Aceito em 05 de maio de 2013. O artigo foi avaliado segundo o processo de duplo anonimato além de ser avaliado pelo editor. Editores responsáveis: Márcio Augusto Gonçalves e Lucas Maia dos Santos. Reprodução parcial ou total e trabalhos derivativos permitidos com a citação apropriada da fonte.
} 
Revista de Administração Hospitalar, v.10, n.3, pp. 1-16, setembro/dezembro, 2013/ Carlos Eduardo Alarcon Pizzorno, Vivian Osmari Uhlmann, Elisete Dahmer Pfitscher

\begin{abstract}
Resumen
El objetivo general del estudio es verificar la sostenibilidad del medio ambiente de un hospital en el estado de Rio Grande do Sul, a través de la aplicación parcial del Sistema de Contabilidad de Gestión Ambiental SICOGEA - Generación 3. El proceso de recolección de datos ocurrió con la aplicación de una lista de control con 134 preguntas divididas por grupos principales y subgrupos. Basándose en los resultados, se verificó un índice de sostenibilidad global de 30,60 \%, que se considera débil. Esto indica que el proceso de prestación de servicios hospitalarios puede ser la causa de los impactos ambientales negativos. Tenga en cuenta que el grupo clave que más contribuyó en el índice general fue el "Servicio de Entrega", con el 35,61 \%. Por otra parte, el grupo clave que presenta el peor resultado fue "Finanzas y Contabilidad ", con el 12,78\%, esto es debido a que el hospital no cuenta con un Sistema de Gestión Ambiental, o bien no hay un plan para la calidad ambiental. Después de la identificación de los puntos críticos en materia de sostenibilidad estructuró un Resumen del Plan de Manejo Ambiental, que incluye acciones para mejorar el desempeño ambiental, tales como el diseño e implementación de un manual con metas e indicadores de desempeño.
\end{abstract}

Palabras clave: sostenibilidad del medio ambiente. El Hospital. Contabilidad Ambiental.

\title{
1 INTRODUÇÃO
}

A conscientização da sociedade está fazendo com que as empresas adotem uma postura responsável perante o meio ambiente, isto significa produzir sem agressão à natureza. A consciência ecológica impulsiona a adoção de políticas e ações a favor da preservação do meio ambiente. As empresas que procuram manterem-se competitivas percebem, diante das questões ambientais, que são exigidas novas posturas na maneira de operar seus negócios.

Segundo Kraemer (2001, p.72), as "empresas experientes identificam resultados econômicos e resultados estratégicos do engajamento da organização na causa ambiental". Muitas empresas estão habituadas, em seus sistemas de custos, a não diferenciar as atividades que agregam valor das que não agregam valor aos produtos, nem tampouco identificam e incorporam em seus sistemas de custos os chamados custos ambientais. A Contabilidade pode auxiliar os administradores no gerenciamento empresarial do meio ambiente, principalmente no que se refere à Responsabilidade Social e Ambiental das empresas.

À medida que ações e projetos ambientais são implantados nas entidades, podem surgir eventos que afetam diretamente o patrimônio das entidades. Logo, tais ações ambientais devem ser evidenciadas por meio de relatórios contábeis, com o objetivo de esclarecer a relação entre a organização e o meio ambiente.

O presente estudo trata de um estudo de caso em um hospital, limitando-se as áreas de: gestão ambiental, contabilidade e auditoria ambiental e suas normas vigentes, por meio do método SICOGEA - Sistema Contábil Gerencial Ambiental, especificamente da terceira etapa da primeira fase.

Nesta perspectiva, a problemática deste trabalho fica resumida na seguinte questãoproblema: como se encontra a sustentabilidade ambiental de um hospital gaúcho?

Com isso, o objetivo geral do estudo consistiu em verificar a sustentabilidade ambiental de um hospital do Estado do Rio Grande do Sul, por meio da aplicação parcial do Sistema Contábil Gerencial Ambiental - Geração 3. Para atender ao objetivo central foi necessário desenvolver os seguintes objetivos específicos: verificar o processo de prestação de serviços do hospital; realizar um diagnóstico das atividades hospitalares com potencial de impactar negativamente o meio ambiente; definir os grupos-chave, subgrupos e pontos possíveis da lista de verificação; analisar os índices de sustentabilidade do hospital e identificar os elementos que respondem pelos menores desempenhos ambientais; e propor um plano resumido de gestão ambiental.

Em um sentido amplo, esta pesquisa pretende demonstrar a importância da aplicação da Contabilidade Ambiental na área da saúde. 
Nesta pesquisa, optou-se pela utilização do SICOGEA-Geração 3, que se constitui em uma ferramenta de gestão do meio ambiente, por ser capaz de proporcionar à entidade um subsídio consistente a avaliação dos seus aspectos e impactos sobre o ambiente, com base no seu gerenciamento ambiental. Este sistema pode, ainda, destacar formas de melhor gerir os eventos ambientais, uma vez que une, por meio de controles, a Contabilidade ao meio ambiente (PFITSCHER, 2004; UHLMANN, 2011).

A importância de realizar um trabalho sobre a sustentabilidade ambiental em relação às ações das organizações hospitalares, explica-se pelo fato do tema cada vez mais ganhar espaço nos diversos meios de comunicação e a necessidade crescente de esclarecimentos relacionados aos mesmos.

A contribuição prática do trabalho consiste em analisar e verificar resultados e melhorias que podem ser feitas no gerenciamento ambiental dentro de uma instituição hospitalar. Na contribuição da pesquisa em termos teóricos, tem-se uma ferramenta que auxilia as companhias a controlar e fiscalizar os processos de trabalho para que estejam dentro dos padrões exigidos pelas normas ambientais e conseqüiente redução de custos ambientais.

\section{FUNDAMENTAÇÃO TEÓRICA}

A fundamentação teórica da presente pesquisa é composta pelas teorias a seguir relacionadas, que darão suporte à análise dos resultados.

\subsection{Contabilidade e Gestão Ambiental}

A Contabilidade como ciência social tem como objeto o estudo do patrimônio, e seu objetivo é registrar, evidenciar e mensurar todos os fatos relacionados com as variações patrimoniais. Diante disso, percebe-se que o registro e o controle de informações contábeis podem contribuir de forma positiva no campo de proteção ambiental, com dados econômicos e financeiros resultantes das interações de entidades que se utilizam da exploração do meio ambiente.

Uhlmann (2011,p. 26) afirma que, "a Contabilidade Ambiental pode ser entendida como um sistema que identifica, registra, processa e gera informações sobre como a empresa está se relacionando com o meio ambiente". Corroborando esta afirmação Carvalho (2010, p. 111) menciona que a "Contabilidade Ambiental pode ser definida como o destaque dado pela ciência aos registros e evidenciações da entidade referentes aos fatos relacionados com o meio ambiente."

Logo, a Contabilidade Ambiental registra as transações da empresa ou organização que impactam o meio ambiente assim como os seus efeitos, ou seja, é o registro do patrimônio ambiental e suas respectivas variações. Um dos seus principais objetivos é propiciar informações regulares aos usuários internos e externos acerca dos eventos ambientais que causaram modificações na situação patrimonial da respectiva entidade.

Neste sentido, Paiva (2006, p.18) afirma que:

A Contabilidade Ambiental reflete diretamente o nível de conscientização ambiental da sociedade, evoluindo de acordo com o grau de entendimento quanto à importância do meio ambiente na vida do ser humano, e uma preocupação quanto à sustentabilidade dos recursos frente às necessidades básicas da população.

Complementando, Uhlmann (2011, p.13) diz que "para uma gestão com enfoque ambiental, é preciso conhecer os aspectos e impactos ambientais que as atividades da instituição podem ocasionar ao meio ambiente."

Gallon et al. (2007) salientam que a Contabilidade tem como objetivo principal registrar os eventos internos da entidade, que tenha relação com o meio ambiente, seus aspectos e seus efeitos que possam vir ocorrer, ou seja, os impactos de uma gestão inadequada desses recursos. Sendo assim pode-se destacar que a empresa ao gerenciar os efeitos 
ambientais, pode obter benefícios que se mostram de duas formas: a primeira é econômica, quando da existência de uma redução nos custos, podendo haver um aumento da receita e a segunda é o estratégico, relacionado diretamente com a imagem da empresa perante a sociedade.

O Instituto Brasileiro de Contadores (IBRACON) aprovou em 1996 a Norma de Procedimento de Auditoria $\mathrm{N}^{\circ} 11$ - Balanço e Ecologia, proporcionando um plano a ser examinado pelos contadores nos casos de implicações com o meio ambiente, tendo como finalidade o estabelecimento das junções entre a contabilidade e o meio ambiente. Assim como as demais ciências, incumbe-lhe, também, participar dos esforços em favor da defesa e proteção contra a poluição e as agressões à vida humana e à natureza.

$\mathrm{Na}$ visão de Tinoco e Kraemer (2008), a gestão ambiental equivale a desenvolver e implementar um sistema que integra a estrutura organizacional de planejamento, responsabilidades, práticas, procedimentos e recursos com o intuito de implantar, atingir, analisar e cultivar uma política ambiental, ou seja, são as ações que a empresa procura fazer para reduzir ou eliminar os resultados negativos provocados no ambiente em função de suas atividades.

De acordo com Pfitscher (2004, p. 51), ao realizar um Sistema de Gestão Ambiental visa-se uma melhor estabilidade e sustentabilidade, pois há que se obter um comprometimento de todos os envolvidos. Para tanto, desenvolve-se um sistema de princípios em busca de vantagens competitivas, organizacionais, entre outras.

Logo, o sistema de gestão ambiental pode permitir que a empresa ou organização atinja o nível de desempenho ambiental por ela estipulado e promova sua melhoria ao longo do tempo, visando à eliminação ou minimização dos impactos ao meio ambiente, por meio de ações preventivas ou medidas atenuadoras.

\subsection{Externalidades Positivas e Negativas}

As empresas podem ser concebidas como sistemas abertos, logo, os processos produtivos possuem relações inerentes entre si. Assim, toda produção de bens ou serviços de uma empresa afetará outras empresas ou pessoas envolvidas. Embora esses efeitos sejam de difícil avaliação em termos de quantificação, podem-se identificar as origens de seus custos e atribuí-lo ao seu gerador.

Segundo Mankiw (2005, p.204) "a caracterização das contribuições negativas e positivas se baseará no conceito de externalidades, sendo considerada como negativa quando o impacto sobre terceiros for adverso; e positiva quando este impacto for benéfico."

Hansen e Mowen (2003, p.567) afirmam que "os custos ambientais estão associados com a criação, detecção, correção e prevenção da degradação ambiental".

Logo, os custos ambientais deveriam ser tratados como os gastos realizados para minimizar ou eliminar os efeitos dos impactos das atividades realizadas pelas empresas com o meio ambiente.

Ainda, Vasconcellos e Garcia (2004, p. 225) afirmam que as externalidades ocorrem quando "a produção ou o consumo de um bem acarreta efeitos sobre outros indivíduos, e esses custos/benefícios não se refletem nos preços".

Percebe-se, dessa maneira, que a identificação dos custos ambientais não é tarefa fácil, já que existem muitos que são de natureza intangível, por isso, são de difícil mensuração. O que ocorre na verdade é uma identificação e mensuração dos custos referentes às externalidades com a preservação e recuperação por danos causados, ou custos para evitar os danos ocasionados pelos impactos decorrentes da má utilização do meio ambiente, assim como a apuração dos custos envolvidos na preservação. (SILVA et al., 2003)

A Gestão Ambiental correlacionada aos aspectos econômico-contábeis poderia ajudar na identificação dos custos ambientais gerados pelas atividades e processos organizacionais. 
Revista de Administração Hospitalar, v.10, n.3, pp. 1-16, setembro/dezembro, 2013/ Carlos Eduardo Alarcon Pizzorno, Vivian Osmari Uhlmann, Elisete Dahmer Pfitscher

Dessa forma, a empresa pode estabelecer planos de ações e mecanismos de controle com o objetivo de diminuir ou eliminar tais custos, podendo melhorar assim a eficiência da utilização de recursos da companhia, fator chave para acumulação de riquezas.

"Observa-se que muitas empresas desembolsam centenas de milhões de dólares a cada ano em implantação de políticas ambientais. No entanto, as decisões ambientais são tomadas com pouco apoio do sistema de informações da gestão de custos." (HANSEN; MOWEN, 2003, p.564)

É interessante salientar que se tais custos fossem possíveis de ser internalizado, isso, representaria um passo importante para controlar o uso dos recursos e serviços naturais, tendo como resultado induzir os consumidores a pagar o custo real do bem adquirido, ao invés de repassá-los à sociedade.

\subsection{Sistemas de Gestão Ambiental}

De acordo com Lerípio (2001), o método da Gestão dos Aspectos e Impactos Ambientais (GAIA) é uma ferramenta que é utilizada para demonstrar o desempenho ambiental das organizações, sendo o seu foco a sustentabilidade ambiental, seus aspectos e impactos, visando à melhoria continua e a prevenção.

O Sistema Contábil Gerencial Ambiental (SICOGEA) foi projetado por Pfitscher (2004). Inicialmente, o foco de aplicação deste instrumento foram as empresas rurais, fazendo com que se utilizasse terminologias próprias da área. No entanto, este método pôde ser adaptado e aplicado à empresas de vários setores e portes.

Segundo Pfitscher (2004), o SICOGEA é um instrumento de gestão ambiental, que conecta a contabilidade ao meio ambiente, através de controles. O objetivo desse sistema é gerar informações ao gestor sobre os impactos das suas ações no meio ambiente. E, teve sua origem no método GAIA.

O SICOGEA é dividido em três etapas, quais sejam: i) integração da cadeia produtiva, ii) gestão e controle ecológico e iii) gestão da contabilidade e controladoria ambiental, sendo que cada uma dessas etapas possui várias fases.

Esta terceira etapa é composta de três fases, a saber: a primeira da Investigação e mensuração, que integra três itens: a) Sustentabilidade e estratégia ambiental, b) Comprometimento e c) Sensibilização das partes interessadas; a segunda fase é a da Informação que integra três itens: i) inventário de aspectos e impactos ambientais, ii) estudo de entradas e saídas do processo e iii) mapeamento da cadeia de produção e macrofluxo do processo ; e, a terceira fase da Decisão, que também é integrada por três itens, a saber: I) planejamento, II) estudo de viabilidade e III) oportunidades de melhoria. A Figura 1 ilustra a estrutura da terceira etapa.

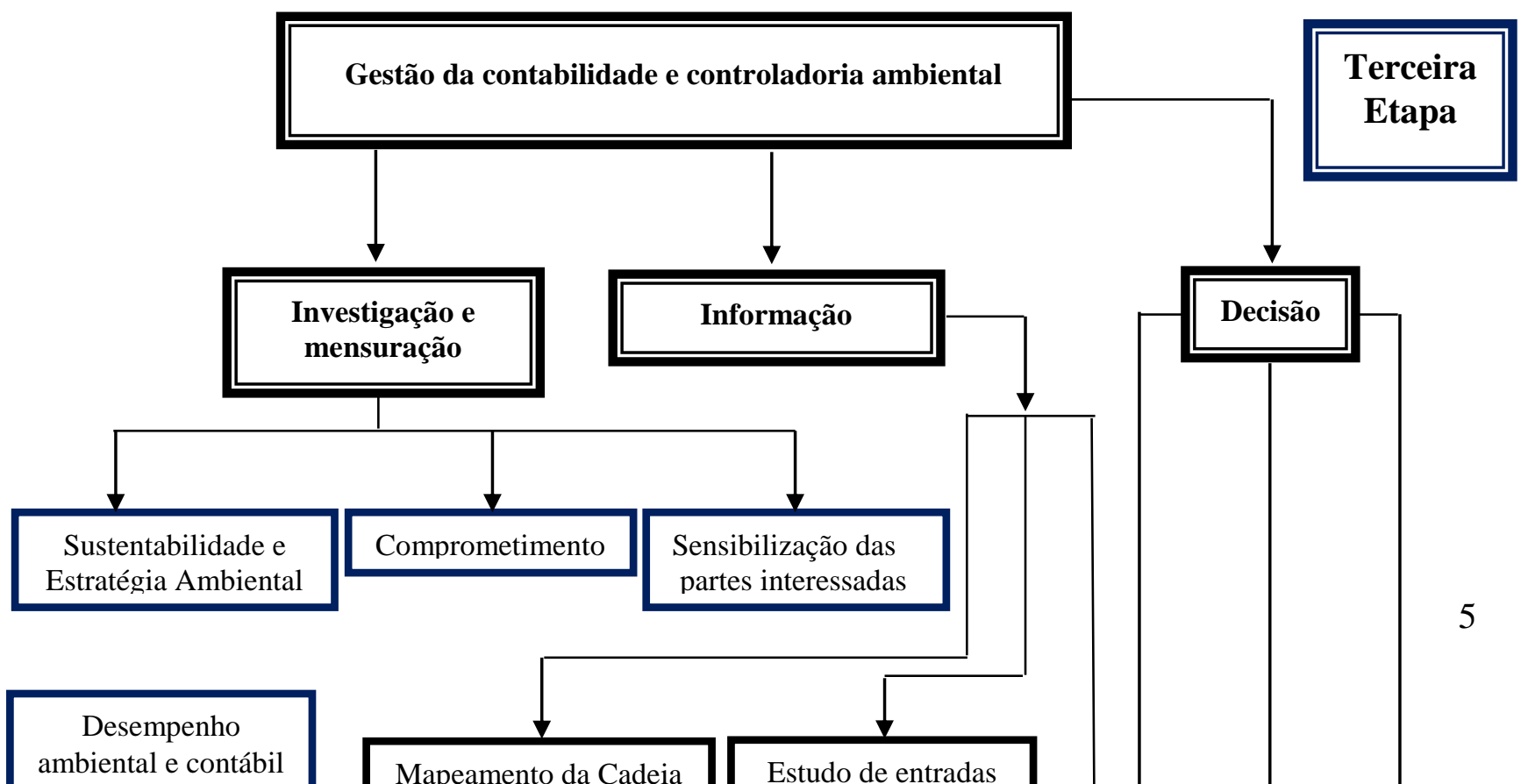


Figura 1 - Estrutura da terceira etapa

Fonte: adaptada de Pfitscher (2004), Nunes (2010) e Uhlmann (2011)

Ao estudar a metodologia do SIGOGEA, Nunes (2010) propôs algumas adaptações e melhorias ao método e obteve, como resultado do seu estudo, a segunda geração do SICOGEA.

De acordo com Nunes (2010, p. 155-156):

O SICOGEA - Geração 2 (Sistema Contábil Gerencial Ambiental - Geração 2) é uma ferramenta de gestão ambiental, que une contabilidade por meio de controles, trabalhando com fatores ambientais, econômicos e sociais, gerando informações aos gestores, buscando melhorar a atuação das atividades das entidades sob o meio ambiente.

As principais mudanças sugeridas pelo SICOGEA - Geração 2 foram: alteração na estrutura da lista de verificação; lista dividida por grupos-chave e subgrupos; inclusão de questões-chave nos itens da lista; forma de respostas de 0 (zero) a 5 (cinco); atribuição de pontos diferentes por questão, a critério do analista; inclusão de planilha de ponderação; outra estrutura de indicadores; inclusão de duas fórmulas para identificar os índices de eficiência dos itens; e sugestão de estrutura do 5W2H para as aplicações futuras (NUNES,2010).

$\mathrm{Na}$ pesquisa realizada por Uhlmann (2011), que teve como objeto de análise o SICOGEA - geração 2, foram realizadas uma série de contribuições de melhoria ao sistema e, assim, proposto o SICOGEA - geração 3 .

Uhlmann (2011) apresenta o SICOGEA - Geração 3 na forma de um aporte ao método precursor. A autora enfatiza que não houve alteração na estrutura do SICOGEA - Geração 2 com a exclusão de ações, bem como não houve mudança na metodologia de cálculo dos índices de sustentabilidade ambiental. $\mathrm{O}$ que se sucedeu foi a inserção e a reorganização de ações, com vistas a potencializar os resultados e a facilitar a aplicação do sistema.

A lista de verificação adaptada integra a primeira fase da etapa três, onde se tem a investigação e mensuração.

\subsection{Ecoeficiência e Resíduos dos Processos Hospitalares}

A Ecoeficiência pode ser definida como uma gestão através do qual se pode relacionar competitividade e desenvolvimento sustentável com objetivo de criar e promover resultados com o menor impacto ambiental possível.

Essa afirmação é reforçada por Vellani et al. (2009, p. 27):

A ecoeficiência significa integrar desempenho econômico e ecológico. Para isso, os gastos incorridos nas atividades ambientais devem gerar benefício econômicofinanceiro (desempenho econômico) e a finalidade dessas ações deve ser atuar sobre os resíduos emitidos pela própria empresa durante o processamento de seus produtos e serviços (desempenho ambiental da própria empresa). 
Conforme Hansen e Mowen (2003), na gestão das organizações podem-se produzir bens e serviços de qualidade e simultaneamente reduzir os impactos ambientais negativos atacando-se as causas, em vez das consequências.

Logo, pode-se dizer que a ecoeficiência implicaria a produção de bens e a prestação de serviços a preços mais competitivos que satisfaçam as necessidades humanas e elevem a qualidade de vida das pessoas sem comprometer com isso o meio ambiente, promovendo a diminuição progressiva dos impactos ambientais negativos provocados pelos produtos.

A ecoeficiência pode-se constituir como um dos meios mais adequados para que as empresas possam avaliar o seu desempenho ambiental e produtivo. Ela deveria ser vista como uma oportunidade de assumir a responsabilidade empresarial junto ao meio ambiente.

Além disso, Vellani et al. (2009, p. 27) afirmam que as "empresas que não mantêm ações para atuar sobre seus próprios resíduos não são capazes de integrar desempenho ecológico e econômico".

Por tanto, se uma empresa consegui-se implementar um programa de ecoeficiência, esta poderia trazer resultados positivas para o desenvolvimento sustentável, contribuindo, assim, para a criação de um equilíbrio ambiental do planeta.

De outra parte, o hospital é uma "instituição destinada a internar, para diagnóstico e tratamento, pessoas que necessitam assistência médica diária e cuidados constantes de enfermagem" (RIBEIRO, 1977, p. 25).

Pode-se dizer que os hospitais assemelham-se a empresas no momento em que possuem bens e direitos, obrigações, custos, despesas e receitas. Tais recursos proporcionam a execução das atividades hospitalares, garantindo atendimento adequado aos pacientes.

Um hospital, apesar de não desenvolver seus trabalhos por meio de processos operacionais industriais, possui atividades de alto impacto ambiental por meio da geração de Resíduos dos Serviços de Saúde (RSS), há uma evidente preocupação existente quanto ao tratamento dado aos resíduos excedentes das atividades dos hospitais, por se tratar de substâncias que podem trazer contaminações e prejudicar a qualidade do meio ambiente.

$\mathrm{Na}$ busca de informações relevantes para tais entidades, os gestores podem utilizar as formas de controle geradas pela contabilidade obtendo um gerenciamento dos aspectos e impactos ambientais.

Segundo Ferreira (1995), os resíduos hospitalares são produzidos em unidades de saúde, compostos de lixo comum (papel, restos de comida de refeitórios e cozinhas etc), resíduos infectantes ou de risco biológico (sangue, gaze, curativos, agulhas etc) e resíduos especiais (químicos, farmacêuticos e radioativos).

A má gestão dos resíduos hospitalares pode representar risco à saúde, assim como impactos ambientais em função do destino desses resíduos.

\section{METODOLOGIA DA PESQUISA}

A metodologia utilizada no presente trabalho é de natureza descritiva, pois em tal forma de pesquisa busca-se, dentro do objeto de estudo, identificar suas variáveis, relatar e comparar. Para Raupp e Beuren (2003, p. 81), “[...] descrever significa identificar, relatar, comparar entre outros aspectos".

Realizada por meio de estudo de caso que, de acordo com Gil (2002, p. 54), "Consiste no estudo profundo e exaustivo de um ou poucos objetos, de maneira que permita seu amplo e detalhado conhecimento [...]", esta modalidade de pesquisa busca um aprofundamento da questão estudada, tendo como único foco de análise e fonte de obtenção dos dados utilizados um hospital de Porto Alegre, através de entrevistas semi-estruturadas e abordagem qualitativa dos dados.

Como trajetória metodológica utilizada na realização do trabalho tem-se uma divisão em três fases. A primeira fase trata da fundamentação teórica. Na segunda apresenta-se um 
estudo de caso, com um breve histórico do Hospital e a aplicação de uma lista de verificação com 134 questões voltadas para hospitais, dividida por grupos-chave e subgrupos. Na terceira e última fase apresenta-se uma proposta de Plano resumido de Gestão Ambiental, utilizandose da ferramenta 5W2H: What?; Why?; When?; Where?; Who?; How? e How much?.

Assim, a pesquisa buscou investigar qual o tratamento que a instituição hospitalar confere às atividades referentes à recuperação, proteção e reciclagem ambiental, através da aplicação parcial do método SICOGEA - Geração 3. A escolha do hospital de Porto Alegre foi por acessibilidade aos dados necessários ao desenvolvimento da pesquisa, porém, será mantido em sigilo o nome da instituição, assim como do responsável.

O processo de coleta de dados ocorreu com a aplicação de uma lista de verificação direcionada à atividade, tendo sido adaptada do estudo de Nunes (2010). Esse instrumento de pesquisa compõe a primeira fase da terceira etapa do SICOGEA - Geração 3 e tem por finalidade colher e classificar a percepção do entrevistado quanto à conduta da instituição em relação ao meio ambiente. De posse dos dados da lista de verificação, prosseguiu-se o cálculo dos índices de sustentabilidade.

A lista de verificação utilizada foi dividida por grupos-chave e subgrupos, concentrando variáveis inerentes ao processo de prestação de serviços hospitalares, conforme apresentado na Tabela 1:

Tabela 1 - Grupos-chave e subgrupos investigados na pesquisa

\begin{tabular}{|c|c|c|}
\hline \multicolumn{3}{|c|}{$\begin{array}{l}\text { LISTA DE VERIFICAÇÃO DO SICOGEA - GERAÇÃO } 2 \\
\text { GRUPO-CHAVE E SUBGRUPOS }\end{array}$} \\
\hline GRUPO & GRUPO-CHAVE & SUBGRUPOS \\
\hline \multirow{4}{*}{1} & \multirow{4}{*}{ Prestação de Serviço } & Fornecedores \\
\hline & & Processos de Prestação de Serviços \\
\hline & & Tratamento de Resíduos \\
\hline & & Manutenção \\
\hline \multirow{2}{*}{2} & \multirow{2}{*}{ Recursos Humanos } & Equipe de Colaboradores \\
\hline & & Gestão da Instituição \\
\hline 3 & Marketing & Responsabilidade Sócio Ambiental \\
\hline 4 & Finanças e Contabilidade & Contabilidade e Auditoria Ambiental \\
\hline
\end{tabular}

Fonte: adaptado de Nunes (2010)

Nunes (2010) define uma classificação com as percentagens e suas devidas significações no atendimento ao tema avaliado, informado pelo respondente, apresentadas na Tabela 2:

Tabela 2 - Estrutura do modelo de avaliação adaptado na pesquisa

\begin{tabular}{|c|c|c|}
\hline \multicolumn{3}{|c|}{$\begin{array}{l}\text { MODELO DE AVALIAÇÃO } \\
\text { LISTA DE VERIFICAÇÃO DO SICOGEA - GERAÇÃO } 2\end{array}$} \\
\hline ESCALA & DEMONSTRA & ESCORE \\
\hline 0 & Nenhum investimento/controle sobre o item avaliado & $0 \%$ \\
\hline 1 & Algum investimento/controle sobre o item avaliado & $20 \%$ \\
\hline 2 & Investimento/controle um pouco maior que no item anterior, sobre o item avaliado & $40 \%$ \\
\hline 3 & Investimento/controle um pouco maior que no item anterior, sobre o item avaliado & $60 \%$ \\
\hline 4 & Investimento/controle um pouco maior que no item anterior, sobre o item avaliado & $80 \%$ \\
\hline 5 & Investimento/controle total sobre o item avaliado. & $100 \%$ \\
\hline
\end{tabular}

Apresentada a estrutura da lista de verificação, o pesquisador confere a pontuação de cada questão conforme critérios por ele definidos. Porém, o respondente não deve ser informado destes valores para não distorcer sua resposta. A pontuação alcançada por cada questão é obtida a partir do produto entre o escore referente ao tema avaliado, informado pelo respondente, e o total de pontos possíveis na questão, atribuído pelo analista. 
Revista de Administração Hospitalar, v.10, n.3, pp. 1-16, setembro/dezembro, 2013/ Carlos Eduardo Alarcon Pizzorno, Vivian Osmari Uhlmann, Elisete Dahmer Pfitscher

A atribuição dos pontos possíveis às questões seguiu o procedimento proposto pelo SICOGEA - Geração 3. Realizou-se uma analise por parte dos pesquisadores com vistas a diagnosticar os aspectos ambientais com iminente potencial de impactar negativamente o meio ambiente. Com isso, pôde-se seguir um padrão na estruturação da lista de verificação, o que veio a atribuir maior participação dos aspectos potencialmente impactantes no resultado.

Objetivando maior controle do processo de atribuição dos pontos possíveis, escore e pontos alcançados, criou-se uma planilha de ponderação, cujo modelo é demonstrado na Tabela 3.

Tabela 3 - Planilha de cálculo

\begin{tabular}{|c|c|c|c|c|c|c|c|c|c|c|c|}
\hline \multicolumn{12}{|c|}{$\begin{array}{c}\text { MODELO DE PLANILHA DE CÁLCULO } \\
\text { LISTA DE VERIFICAÇÃO DO SICOGEA - GERAÇÃO } 2\end{array}$} \\
\hline \multirow{2}{*}{\multicolumn{3}{|c|}{ PERGUNTA }} & 0 & $20 \%$ & $40 \%$ & $60 \%$ & $80 \%$ & $100 \%$ & Pontos & & \\
\hline & & & 0 & 1 & 2 & 3 & 4 & 5 & possíveis & Escore & Pontos \\
\hline \multirow{13}{*}{ 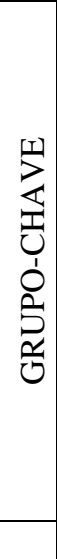 } & 1 & \multirow{12}{*}{ 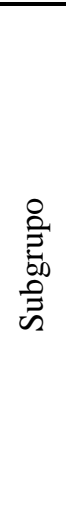 } & & & & & $X$ & & 1 & $80 \%$ & 0,8 \\
\hline & 2 & & & & & $X$ & & & 1 & $60 \%$ & 0,6 \\
\hline & 3 & & & & $X$ & & & & 1 & $40 \%$ & 0,4 \\
\hline & 4 & & & $X$ & & & & & 1 & $20 \%$ & 0,2 \\
\hline & 5 & & & & & & $X$ & & 1 & $80 \%$ & 0,8 \\
\hline & 6 & & & & $X$ & & & & 1 & $40 \%$ & 0,4 \\
\hline & 7 & & & & & $X$ & & & 1 & $60 \%$ & 0,6 \\
\hline & 8 & & & & & & & $X$ & 2 & $100 \%$ & 2 \\
\hline & 9 & & & & & & $X$ & & 2 & $80 \%$ & 1,6 \\
\hline & 10 & & & & & & & $X$ & 2 & $100 \%$ & 2 \\
\hline & 11 & & $X$ & & & & & & 1 & 0 & 0 \\
\hline & 12 & & & & & & & $X$ & 5 & $100 \%$ & 5 \\
\hline & & \multicolumn{7}{|c|}{ Total } & 19 & & 14,4 \\
\hline
\end{tabular}

Fonte: adaptada de Nunes et al. (2009 apud Uhlmann, 2011 p.48)

Após a obtenção dos pontos de cada grupo-chave e subgrupo, pode-se prosseguir com o cálculo do índice geral de sustentabilidade, utilizando a seguinte expressão matemática:

$$
\text { İndice de Sustentabilidade }=\frac{\text { Pontos alcançados }}{\text { Pontos possíveis }} \times 100
$$

Figura 2 - Fórmula do índice geral de sustentabilidade

Fonte: adaptada de Nunes (2010, apud Uhlmann, 2011 p.49)

Os índices de sustentabilidade calculados a partir da referida fórmula correspondem, cada qual, a um estágio de desempenho ambiental, conforme relacionado na Tabela 4.

Tabela 4 - Avaliação da sustentabilidade e desempenho ambiental segundo o SICOGEA-Geração 2

\begin{tabular}{c|c|l}
\hline Resultado & Sustentabilidade & \multicolumn{1}{c}{ Desempenho: controle, incentivo, estratégia } \\
\hline Inferior a 20\% & Péssimo - 'P' & Pode estar causando grande impacto ao meio ambiente \\
\hline Entre 21 e 40\% & Fraco - 'F' & $\begin{array}{l}\text { Pode estar causando danos, mas surgem algumas poucas } \\
\text { iniciativas }\end{array}$ \\
\hline Entre 41 e 60\% & Regular - 'R' & $\begin{array}{l}\text { Atende somente à legislação } \\
\text { Entre 61 e } 80 \%\end{array}$ \\
\hline Bom - 'B' & $\begin{array}{l}\text { Além da legislação, surgem alguns projetos e atitudes que buscam } \\
\text { valorizar o meio ambiente }\end{array}$ \\
\hline Superior a $80 \%$ & Ótimo - 'O' & $\begin{array}{l}\text { Alta valorização ambiental com produção ecológica e prevenção } \\
\text { da poluição }\end{array}$ \\
\hline
\end{tabular}

Fonte: adaptada de Lerípio (2001), Pfitscher (2004) e Nunes (2010) 
Revista de Administração Hospitalar, v.10, n.3, pp. 1-16, setembro/dezembro, 2013/ Carlos Eduardo Alarcon Pizzorno, Vivian Osmari Uhlmann, Elisete Dahmer Pfitscher

Nunes (2010) propõe outra forma de análise no que diz respeito ao cálculo da contribuição dos grupos-chave e subgrupos, com a intenção de igualar a participação destes no resultado geral da sustentabilidade. Deste modo, a fórmula é utilizada para equalizar o potencial de cada grupo-chave ou subgrupo, visando saber se contribuiu positiva ou negativamente para o resultado final.

A seguinte expressão matemática (Figura 3) pode ser utilizada para o cálculo do percentual de contribuição de cada grupo-chave.

$\%$ Contribuição Grupo - Chave $\left.=\frac{\left[\left(\frac{\text { Total de pontos alcançados }}{\text { Total de possiveis do grupo }- \text { chave }}\right) x\left(\frac{100}{n \cdot{ }^{\circ} \text { total de grupos }- \text { chave }}\right)\right]}{100}\right]$

Figura 3 - Fórmula do percentual de contribuição de cada grupo-chave

Fonte: Nunes (2010, p. 170)

Esta fórmula consiste na soma total dos pontos possíveis do grupo-chave, dividido pelo número total de pontos alcançados no mesmo, multiplicados pelo fator de contribuição de cada grupo-chave, sendo que este é obtido por 100 dividido pelo número de grupos-chave da lista de verificação. Após isso, divide-se por 100, para obter o percentual de participação no resultado, de cada grupo-chave.

Igualmente ao cálculo da contribuição dos grupos-chave, realiza-se o cálculo para saber a participação de cada subgrupo e, desta forma, possibilitar a identificação dos itens prioritários para atendimento na gestão ambiental. Assim, apresenta-se a Fórmula 02 (Figura 4).

$\%$ Contribuição do subgrupo $=\frac{\left[\left(\frac{\text { Total de pontos alcançados }}{\text { Total de pontos possíveis do subgrupo }}\right) x\left(\frac{100}{n .^{\circ} \text { total de subgrupos do questionário }}\right)\right]}{100}$

Figura 4 - Fórmula do percentual de participação de cada subgrupo

Fonte: Nunes (2010, p. 170)

Esta fórmula consiste na busca da contribuição de cada subgrupo, em relação à lista de verificação ou a cada Grupo-chave individualmente, caso o analista desejar. Para isso, utilizase o total de pontos possíveis para cada subgrupo, divide-se pelo total de pontos alcançados, multiplicando os mesmos pelo fator de participação, que é obtido com 100 dividido pelo número total de subgrupos do questionário ou grupo-chave e, por fim, dividindo-se este número obtido por 100 .

\section{ANÁLISE DE RESULTADOS}

Apresenta-se a seguir o estudo de caso num hospital de Porto alegre no Rio Grande do Sul, e visa identificar a sustentabilidade da empresa através da aplicação parcial do SICOGEA - Geração 3. A seguir, tem-se a análise dos índices de sustentabilidade derivados das respostas da lista de verificação aplicada à diretora do hospital. Por fim, apresenta-se uma proposta de plano resumido de gestão ambiental direcionado a organização estudada.

\subsection{Desempenho da sustentabilidade ambiental do hospital}

No contato seguinte, o diretor respondeu às questões da lista de verificação. A cada questão foi atribuído um escore que refletia a realidade da organização, de acordo com a escala de 0 a 5 , detalhada na Tabela 2 . Os pontos possíveis, pontos alcançados, e índice de sustentabilidade geral, por grupos-chave e subgrupos, podem ser visualizados na Tabelas 5 .

Tabela 5 - Pontos possíveis, pontos alcançados e o índice de sustentabilidade geral e por grupos-chave.

Índice de sustentabilidade geral, por grupos-chave e subgrupos 
Revista de Administração Hospitalar, v.10, n.3, pp. 1-16, setembro/dezembro, 2013/ Carlos Eduardo Alarcon Pizzorno, Vivian Osmari Uhlmann, Elisete Dahmer Pfitscher

\begin{tabular}{l|r|r|c} 
Grupos-chave & Pontos possíveis & Pontos alcançados & Índice \\
\hline PRESTAÇãO DE SERVIÇO & $\mathbf{1 3 2}$ & $\mathbf{4 7 , 0 0}$ & $\mathbf{3 5 , 6 1 \%}$ \\
\hline Fornecedores & 19,00 & 4,80 & $25,26 \%$ \\
\hline Ecoeficiência do Processo & 22,00 & 5,80 & $26,36 \%$ \\
\hline Tratamento de Resíduos & 71,00 & 29,00 & $40,85 \%$ \\
\hline Manutenção & 20,00 & 7,40 & $37,00 \%$ \\
\hline RECURSOS HUMANOS & $\mathbf{5 3 , 0 0}$ & $\mathbf{1 7 , 2 0}$ & $\mathbf{3 2 , 4 5 \%}$ \\
\hline Equipe de Colaboradores & 26,00 & 9,80 & $37,69 \%$ \\
\hline Gestão da Instituição & 27,00 & 7,40 & $27,41 \%$ \\
\hline
\end{tabular}

Índice de sustentabilidade geral, por grupos-chave e subgrupos

\begin{tabular}{l|r|r|c}
\hline Grupos-chave & Pontos possíveis & Pontos alcançados & \multicolumn{1}{c}{ Índice } \\
\hline MARKETING & $\mathbf{1 3 , 0 0}$ & $\mathbf{2 , 8 0}$ & $\mathbf{2 1 , 5 4 \%}$ \\
\hline Responsabilidade Sócio Ambiental & 13,00 & 2,80 & $21,54 \%$ \\
\hline FINANÇAS E CONTABILIDADE & $\mathbf{3 6 , 0 0}$ & $\mathbf{4 , 6 0}$ & $\mathbf{1 2 , 7 8 \%}$ \\
\hline Contabilidade e Auditoria ambiental & 36,00 & 4,60 & $12,78 \%$ \\
\hline TOTAL & $\mathbf{4 6 8}$ & $\mathbf{1 4 3 , 2}$ & $\mathbf{3 0 , 6 0 \%}$ \\
\hline
\end{tabular}

Fonte: dados pesquisados

Analisando a Tabela 5, observa-se o índice de sustentabilidade geral obtido de $30,60 \%$, que comparando à Tabela 4, verifica-se um grau de sustentabilidade considerado "fraco", demonstrando que a entidade pode estar causando danos, mas surgem algumas poucas iniciativas.

A partir do índice geral de sustentabilidade obtido, buscou-se analisar quanto cada grupo-chave e subgrupo contribuíram para esse desempenho alcançado.

O grupo-chave que mais contribuiu para o índice geral foi o de "Prestação de Serviço" com 35,61\%, destacando-se o subgrupo "Tratamento de Resíduos" com 40,85\%, as questões com maior peso e que receberam a máxima pontuação quanto à sustentabilidade tratavam do lixo ser coletado em sacos plásticos, na cor branca leitosa, conforme especificação da norma ABNT, ou em recipientes apropriados e os sacos de lixo são depositados em caixas metálicas sem tampa, sem que haja a necessidade de abri-los. Na sequencia vem o grupo-chave "Recursos Humanos", com 32,45\%, aqui, pode-se verificar que o subgrupo que mais participou foi "Equipe de Colaboradores" com 37,69\%, nesse item, pode-se constatar que a instituição possui métodos sistematizados de avaliação de desempenho, individual e em equipe, de forma a estimular a obtenção de melhores resultados e o desenvolvimento das pessoas, assim como, participa de projetos sociais como primeiro emprego; emprego a deficientes; bolsa de estágios; entre outros. Entre tanto, o grupo-chave "Marketing" com $21,54 \%$, apresentando o segundo pior resultado em relação ao índice geral, a questão com maior peso e que recebeu avaliação péssima quanto à sustentabilidade tratava da instituição não possuir metas e indicadores de eficiência em marketing. $\mathrm{E}$ o grupo-chave que apresentou o pior resultado foi "Finanças e Contabilidade", com 12,78\%, isto se deve ao fato do hospital não possuir um sistema de gestão ambiental nem existir um plano de qualidade ambiental.

Em seguida, busca-se verificar a participação de cada grupo-chave ajustando seus índices. Para isso, divide-se 100 pelo número de grupos-chave do questionário, sendo que foi obtido o percentual de 25\%. Assim, os índices ajustados de eficiência por processo são apresentados na Tabela 6:

Tabela 6 - percentual de contribuição de cada grupo-chave 
Revista de Administração Hospitalar, v.10, n.3, pp. 1-16, setembro/dezembro, 2013/ Carlos Eduardo Alarcon Pizzorno, Vivian Osmari Uhlmann, Elisete Dahmer Pfitscher

\begin{tabular}{l|r|r}
\hline \multicolumn{2}{c|}{ \% Contribuição de cada grupo-chave - ajustado } & \multicolumn{1}{c}{ Diferença } \\
\hline Prestação de serviço & $8,90 \%$ & $16,10 \%$ \\
\hline Recursos humanos & $8,11 \%$ & $16,89 \%$ \\
\hline Marketing & $5,38 \%$ & $19,62 \%$ \\
\hline Finanças e Contabilidade & $3,19 \%$ & $21,81 \%$ \\
\hline TOTAL & $25,59 \%$ & $74,41 \%$ \\
\hline
\end{tabular}

Fonte: dados pesquisados

A Tabela 6 demonstra que o grupo-chave "Prestação de serviços", foi o que obteve um melhor desempenho, resultando em 8,90\%, faltando apenas 16,10\% para alcançar sua participação máxima no resultado da instituição.

Enquanto o grupo-chave "Finanças e Contabilidade" foi o setor que apresentou o menor índice de eficiência, com 3,19\%, sendo este o setor mais deficitário, necessitando prioridade no atendimento quanto às questões ambientais.

Ainda, Com base nos percentuais da Tabela 5, tem-se que o subgrupo de maior contribuição foi o de "Tratamento de Resíduos", com um índice de 40,85\%, seguido pelo subgrupo "Equipe de Colaboradores" com 37,69\%. Por outro lado, a menor participação foi do subgrupo "Contabilidade e Auditoria ambiental", com 12,78\%.

A Tabela 7 apresenta o índice ajustado de eficiência por subgrupo, de modo que o fator de contribuição para cada subgrupo é obtido dividindo 100 pelo total de subgrupos do questionário, perfazendo um percentual de $12,5 \%$. O resultado pode ser observado na Tabela 7.

Tabela 7 - percentual de contribuição de cada subgrupo

\begin{tabular}{l|r|c}
\hline \multicolumn{2}{c|}{ \% Contribuição de cada subgrupo-ajustado } & Diferença \\
\hline Fornecedores & $3,16 \%$ & $9,34 \%$ \\
\hline Ecoeficiência do Processo & $3,30 \%$ & $9,20 \%$ \\
\hline Tratamento de Resíduos & $5,11 \%$ & $7,39 \%$ \\
\hline Manutenção & $4,63 \%$ & $7,88 \%$ \\
\hline Equipe de Colaboradores & $4,71 \%$ & $7,79 \%$ \\
\hline Gestão da Instituição & $3,43 \%$ & $9,07 \%$ \\
\hline Responsabilidade Socioambiental & $2,69 \%$ & $9,81 \%$ \\
\hline Contabilidade e Auditoria Ambiental & $1,60 \%$ & $10,90 \%$ \\
\hline TOTAL & $28,61 \%$ & $71,39 \%$ \\
\hline
\end{tabular}

Fonte: dados pesquisados

Pode-se observar que o subgrupo "Tratamento de Resíduos" foi o que apresentou um melhor desempenho com $5,11 \%$, faltando apenas $7,39 \%$ para alcançar seu potencial máximo de desempenho. O índice de menor desempenho foi o de "Contabilidade e Auditoria Ambiental", com 1,60\%, faltando 10,90\% para poder alcançar o seu máximo potencial de desempenho.

\subsection{Plano resumido de Gestão Ambiental}

Finalizadas as análises dos índices de sustentabilidade, propõe-se um plano resumido de gestão ambiental observado no Quadro 1, conforme metodologia do SICOGEA-Geração 3. A ferramenta utilizada é o $5 \mathrm{~W} 2 \mathrm{H}$ e os índices que se deseja melhorar o desempenho ambiental são: Finanças e Contabilidade - "Contabilidade e Auditoria Ambiental" e Marketing - "Responsabilidade Sócio Ambiental". 
Revista de Administração Hospitalar, v.10, n.3, pp. 1-16, setembro/dezembro, 2013/ Carlos Eduardo Alarcon Pizzorno, Vivian Osmari Uhlmann, Elisete Dahmer Pfitscher

\begin{tabular}{|c|c|c|c|c|}
\hline \multicolumn{5}{|c|}{ PROJETOS AMBIENTAIS PARA A INDÚSTRIA DE PESCADOS } \\
\hline \multicolumn{3}{|c|}{ ORÇAMENTO PREVISTO } & \multicolumn{2}{|l|}{ QUANTO: Não orçado } \\
\hline \multicolumn{5}{|c|}{ ONDE: Toda a Instituição } \\
\hline O QUE & POR QUE & QUEM & COMO & $\begin{array}{l}\text { QUANDO } \\
\text { (Data } \\
\text { limite) }\end{array}$ \\
\hline$\frac{\sqrt[n]{0}}{\stackrel{0}{\tilde{T}}}$ & $\begin{array}{l}\text { Implementar } \\
\text { novos métodos de } \\
\text { gestão com }\end{array}$ & \multirow{3}{*}{$\begin{array}{c}\text { Diretor ou } \\
\text { Responsável pelo } \\
\text { Departamento de } \\
\text { Administração e } \\
\text { Marketing do } \\
\text { Hospital }\end{array}$} & $\begin{array}{l}\text { Elaborar e implantar um manual com } \\
\text { metas e indicadores de eficiência. }\end{array}$ & Jan/12 \\
\hline 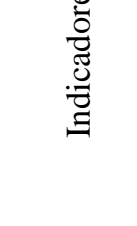 & $\begin{array}{l}\text { contabilidade e } \\
\text { controladoria } \\
\text { ambiental }\end{array}$ & & $\begin{array}{c}\text { Executar as metas e efetuar o constante } \\
\text { monitoramento dos indicadores de } \\
\text { eficiência. }\end{array}$ & abr/12 \\
\hline 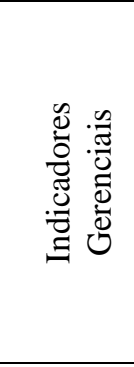 & $\begin{array}{c}\text { Implementar meios } \\
\text { de } \\
\text { melhorar o } \\
\text { controle de } \\
\text { todo } \\
\text { processo, da } \\
\text { administração até o } \\
\text { atendimento } \\
\text { hospitalar } \\
\end{array}$ & & $\begin{array}{l}\text { Acompanhamento de todo o processo } \\
\text { hospitalar e gerenciamento dos recursos } \\
\text { humanos e financeiros }\end{array}$ & abr/12 \\
\hline 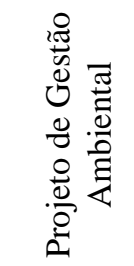 & $\begin{array}{l}\text { Evitar problemas } \\
\text { de Gestão } \\
\text { Ambiental }\end{array}$ & $\begin{array}{l}\text { Pesquisador e } \\
\text { Diretoria do } \\
\text { Hospital }\end{array}$ & $\begin{array}{l}\text { Estudo detalhado para a criação de um } \\
\text { método de gestão ambiental, com } \\
\text { reuniões e troca de informações com } \\
\text { equipe especializada }\end{array}$ & jun/12 \\
\hline
\end{tabular}

Quadro 1 - Plano resumido de gestão ambiental direcionado ao hospital estudado

Fonte: adaptado de Nunes (2010, p. 180)

O índice de sustentabilidade do subgrupo "Responsabilidade Sócio Ambiental" pode ser melhorado caso a empresa procure elaborar metas e estabelecer indicadores contábeis e gerenciais para, melhorar a imagem do Hospital, mostrando interesse em promover ações de envolvimento e preservação socioambiental.

O subgrupo "Contabilidade e Auditoria Ambiental" pode alavancar seu índice de sustentabilidade mediante a criação de um método de gestão ambiental.

O plano resumido é uma ferramenta de auxílio na melhoria do desempenho ambiental. Quando se fala em gestão ambiental, deve-se lembrar que se trata de um trabalho contínuo, que depende de ações que produzem melhorias constantes, com isto, procurando uma redução dos impactos ambientais e da preservação do meio ambiente. 


\section{CONCLUSÃO}

Os modelos de gestão ambiental estão cada vez mais servindo como ferramentas para auxiliar as organizações no gerenciamento dos impactos ambientais causados por suas atividades, principalmente aquelas que oferecem riscos ao meio ambiente.

Este trabalho teve como objetivo analisar e avaliar os impactos ambientais de um Hospital do Rio Grande do Sul, em termos de sustentabilidade. Para tanto, aplicou-se a fase do método SICOGEA - Geração 3 que permite a identificação do índice de sustentabilidade, bem como a avaliação dos aspectos ambientais que oferecem riscos de impactar negativamente o meio ambiente.

Em primeiro lugar procurou-se verificar quais as medidas de gestão ambiental praticadas pela instituição. Pode-se observar durante a realização desta pesquisa, que a mesma não possui uma política de desenvolvimento sustentável.

Em seguida buscou-se identificar os índices de sustentabilidade ambiental, aplicando a primeira fase da terceira etapa do SICOGEA - Geração 3. Assim, foi verificado um índice de sustentabilidade geral de 30,60\%, que conforme comparativo à Tabela 4 é considerado "fraco", demonstrando que a instituição não atende a legislação e apresenta ações que poderiam por em risco o meio ambiente. Foram identificados também, os índices de eficiência por grupo-chave e subgrupos.

A lista de verificação foi dividida em quatro grupos-chave: "Prestação de serviço", "Recursos Humanos", "Marketing", e "Finanças e Contabilidade", sendo que o setor que apresentou um melhor desempenho quanto ao índice de eficiência ajustado por grupo-chave foi o grupo-chave "Prestação de serviço", com 8,90\%, enquanto que o grupo-chave com menor desempenho foi "Finanças e Contabilidade", com 3,19\%. As questões da lista de verificação estavam ainda divididas em oito subgrupos: Fornecedores, Ecoeficiência do Processo, Tratamento de Resíduos, Manutenção, Equipe de Colaboradores, Gestão da Instituição, Responsabilidade Sócio Ambiental, Contabilidade e Auditoria Ambiental. Após análise do índice de eficiência ajustado por subgrupo verificou-se que o subgrupo "Tratamento de Resíduos" apresentou o melhor desempenho, com 5,11\%, enquanto o pior índice encontrado foi o de "Contabilidade e Auditoria Ambiental", com 1,60\%.

Após identificar os pontos críticos quanto à sustentabilidade, estruturou-se um plano resumido de gestão ambiental utilizando a ferramenta $5 \mathrm{~W} 2 \mathrm{H}$, que contemplou ações para melhorar o desempenho do subgrupo "Contabilidade e Auditoria Ambiental" e "Responsabilidade Sócio Ambiental".

A limitação do trabalho ocorre em virtude do fato de se fazer um estudo de caso num hospital específico, não permitindo imediatamente sua utilização em outro tipo de empresa sem as devidas adaptações.

\section{REFERÊNCIAS}

CARVAlHO, Gardenia. M. B. de Contabilidade Ambiental: teoria e prática. Curitiba: Juruá, 2010.

FERREIRA, J. A. Resíduos sólidos e lixo hospitalar: uma discussão ética. Cad. Saúde Públ.,Rio de Janeiro, 11 (2): 314-320, Apr/Jun, 1995.

GALLON, Alessandra V. NUNES, João. PFITSCHER, Elisete D. ALBERTON, Luiz. VIEIRA Eleonora M. F. A Gestão em Hospital Catarinense com o Auxílio da Contabilidade e da Controladoria Ambiental. In: SIMPÓSIO DE ENGENHARIA DE PRODUÇÃO, 14. 2007. Bauru. 
Revista de Administração Hospitalar, v.10, n.3, pp. 1-16, setembro/dezembro, 2013/ Carlos Eduardo Alarcon Pizzorno, Vivian Osmari Uhlmann, Elisete Dahmer Pfitscher

GIL, Antônio Carlos. Como Elaborar Projetos de Pesquisa. 4. ed. São Paulo: Atlas, 2002. (Cap. 4, p. 41-56).

HASEN, Don R.; MOWEN, Maryanne M. Gestão de Custos: Contabilidade e Controle. São Paulo: Pioneira Thomson Learning, 2003

IBRACON - INSTITUTO BRASILEIRO DE CONTADORES. Norma de Procedimento de Auditoria NPA 11 - Balanço e Ecologia. Diretoria Nacional, 1996. Disponível em: $<$ http://www.ibracon.com.br/publicacoes/resultado.asp?identificador=223>. Acesso em: 20 jun. 2011.

KRAEMER, Maria E. P. Contabilidade Ambiental como Sistema de Informação. Revista Contabilidade Vista e Revista, Belo Horizonte, v. 12, n. 3, p. 71-92, dez. 2001.

LERÍPIO, Alexandre de Ávila. GAIA: um método de gerenciamento de aspectos e impactos ambientais. Florianópolis, 2001. Tese (Doutorado em Engenharia de Produção) Programa de Pós-Graduação em Engenharia da Produção, Universidade Federal de Santa Catarina, 2001.

MANKIW, N. Gregory. Introdução à Economia. São Paulo: Pioneira Thomson Learning, 2005 .

NUNES, João Paulo de Oliveira et al.. Contribuições de melhoria para o sistema contábil gerencial ambiental - SICOGEA. In: Congreso Internacional de Costos y Gestión y XXXII Congreso Argentino de Profesores Universitarios de Costos, 11., 2009, Trelew, Chubut e Patagônia. Anais... Argentina: 2006. CD-ROM.

NUNES, João Paulo de Oliveira. Um aporte ao sistema contábil gerencial ambiental: elaboração e aplicação parcial do novo sistema em clínica hospitalar. 2010. 241f. Dissertação (Mestrado em Contabilidade), Programa de Pós-Graduação em Contabilidade, Universidade Federal de Santa Catarina, Florianópolis, 2010.

PAIVA, Paulo R. de. Contabilidade Ambiental: Evidenciação dos Gastos Ambientais com Transparência e Focada na Preservação. São Paulo: Atlas, 2006.

PFISTCHER, Elisete D. Gestão e sustentabilidade através da contabilidade e contabilidade ambiental: estudo de caso na cadeia produtiva de arroz ecológico. 2004. $252 \mathrm{f}$. Tese (Doutorado em Engenharia de Produção) - Curso de Pós-graduação em Engenharia de Produção, Universidade Federal de Santa Catarina. Florianópolis. 2004.

RIBEIRO, A. B. C. Administração de pessoal nos hospitais. 2. ed. São Paulo: FENAME, 1977.

RAUPP, Fabiano Maury; BEUREN, Ilse Maria; LONGARY, André Andrade; SOUZA, Marco Aurélio Batista de; COLAUTO, Romoaldo Douglas; PORTON, Rosimere Alves de Bona. Como Elaborar Trabalhos de Monografias em Contabilidade. In: BEUREN, Ilse Maria. (ORG.). Metodologia da Pesquisa Aplicável às Ciências Sociais: Raupp e Beuren. São Paulo: Atlas, 2003. (Cap. 3, p. 80 - 83).

SILVA, Ivanir S. T.; GASPARETTO, Valdirene.; KLIEMANN NETO, Francisco J.. Uma Aplicação do Custeio Baseado em Atividades para a Apuração de Custos Ambientais em 
um Curtume. In: VIII Congreso del Instituto Internacional de Costos, 2003, Punta Del Este. Anais. Montevideo: AURCO, 2003.

TINOCO, João E. P.; KRAEMER, Maria E. P. Contabilidade e Gestão Ambiental. São Paulo: Atlas, 2008.

UHLMANN, Vivian Osmari. Contribuições ao desenvolvimento do Sistema Contábil Gerencial Ambiental - Geração 2: proposição da terceira geração do método. 2011. 113f. Dissertação (Mestrado em Contabilidade), Programa de Pós-Graduação em Contabilidade, Universidade Federal de Santa Catarina, Florianópolis, 2011.

VASCONCELlOS, Marco A. S.; GARCIA, Manuel E. Fundamentos de Economia. São Paulo: Saraiva, 2004.

VELLANI, Cassio L.; RIBEIRO, Maisa de S. Sistema contábil para gestão da ecoeficiência empresarial. Revista Contabilidade \& Finanças, USP, São Paulo, v.20, n 49, p. 25-43, janeiro/abril 2009. 